Research Article

\title{
The Effect of Al Particles Size on the Thermal Behavior and Kinetics of Al-MnO ${ }_{2}$ Thermite System
}

\author{
Jia-xing Song, Tao Guo $(\mathbb{D}$, Wen Ding, Miao Yao, Li Yang, Xiao-nan Zhang, Zhong-shen Yu, \\ Jia-xiang Wu $\mathbb{D}$, Jun Zhang, and Xiang Fang
}

College of Field Engineering, Army Engineering University of PLA, Nanjing 210007, China

Correspondence should be addressed to Tao Guo; guotao3579@126.com

Received 18 March 2019; Revised 7 March 2020; Accepted 3 April 2020; Published 7 May 2020

Academic Editor: Hongchao Kou

Copyright (C) 2020 Jia-xing Song et al. This is an open access article distributed under the Creative Commons Attribution License, which permits unrestricted use, distribution, and reproduction in any medium, provided the original work is properly cited.

\begin{abstract}
Micron- $\mathrm{MnO}_{2}$ powder has unique thermal decomposition process compared with other metal oxides, and the different characteristics of components in thermite could affect the thermal performance of the whole system directly. In this work, the $\mathrm{Al}$ powder with different three particle sizes was combined with micron- $\mathrm{MnO}_{2}$ to prepare the $\mathrm{Al}-\mathrm{MnO}_{2}$ thermite system, and the effect of $\mathrm{Al}$ powder particle sizes on the whole thermal behavior was studied. Firstly, the thermal decomposition process of micron- $\mathrm{MnO}_{2}$ and purity of $\mathrm{Al}$ powder are tested by TG-DSC. By using ultrasonic dispersion method, the fuel-rich thermite samples were prepared and characterized by SEM and TG-DSC at different heating rates. The Kissinger method was also employed to calculate the activation energy for the first exothermic peak. It was found that the thermal decomposition process of $\mathrm{MnO}_{2}$ in the thermite system can be significantly disturbed by different Al particles size. In other words, the effect of Al particle sizes on the thermite can be magnified due to the unique decomposition properties of micron- $\mathrm{MnO}_{2}$ instead of onset temperature of exothermic reaction changing simply. The activation energy of thermite system decreased with the reduction of Al particle sizes in micron-level, while in nanolevel the activation energy markedly increased. Finally, the possible reasons for phenomenon were discussed.
\end{abstract}

\section{Introduction}

Energetic materials could rapidly release enormous heats and energy during the reaction [1-3]. Thermites, as a kind of energetic materials, are broadly employed in a wide range of applications, including micropropulsion, gas generators, welding, electric igniters, and ammunition primers because of their high adiabatic flame temperature, flame propagation velocity, and energy density [3-7]. In general, thermite systems are the mixture of an oxidizer and fuel.

Aluminum (Al), as a main fuel in thermite system, usually mixes with the other metal oxidizers to form the Albased thermites. The most widely reported Al-based thermites are $\mathrm{Al}-\mathrm{Fe}_{2} \mathrm{O}_{3}, \mathrm{Al}-\mathrm{MoO}_{3}, \mathrm{Al}-\mathrm{WO}_{3}, \mathrm{Al}-\mathrm{CuO}$, and $\mathrm{Al}-$ $\mathrm{KMnO}_{4}$ [7-13]. Hu et al. [7] synthesized the pollen-like porous $\mathrm{Al} / \mathrm{Fe}_{2} \mathrm{O}_{3}$ thermite by a template method. During differential scanning calorimetry (DSC) tests, the reactivity of the thermite is efficiently improved corresponding to its enlarged contact surface area between Al nanoparticle and the pollen-like porous $\mathrm{Fe}_{2} \mathrm{O}_{3}$. The thermal behavior of the metastable intermolecular composite composed of the $\mathrm{Al}$ nanoparticles and $\mathrm{MoO}_{3}$ is studied with DSC tests as a function of the size and size distribution of the Al nanoparticles. And the results indicate that the reactivity of $\mathrm{Al}$ nanoparticles is significantly higher than that of the micronmeter-scale samples [9]. $\mathrm{WO}_{3}$ is of interest as an oxidant for metals in thermites. The nanoscale $\mathrm{WO}_{3}$ is developed by wet chemistry method to make the $\mathrm{Al} / \mathrm{WO}_{3}$ thermite system. And the performance of the $\mathrm{Al} / \mathrm{WO}_{3}$ thermite system is detailed [10]. Besides, $\mathrm{CuO}$ is the common metal oxide added into thermite system as reductant. The thermite reaction between the $\mathrm{CuO}$ nanowires and the deposited nano- $\mathrm{Al}$ is studied. Compared with $\mathrm{CuO}$ and $\mathrm{Al}$ nanopowders mixture, the heat released of $\mathrm{CuO}$ nanowires 
coated with nano-Al is higher, and the higher heat formation mechanism is explained by the intimate contact [11].

But based on Fischer's research, using manganese dioxide $\left(\mathrm{MnO}_{2}\right)$ as metal oxidizer formed the $\mathrm{Al}-\mathrm{MnO}_{2}$ thermite system which also has high heat of reaction theoretically [13] but lacks particular experiments and researches, especially the effect of $\mathrm{Al}$ particles size on the thermal behavior of $\mathrm{Al}-\mathrm{MnO}_{2}$ thermite system. The estimation of isothermal values of activation energy for Al$\mathrm{MnO}_{2}$ thermite system is reported at an early stage [14], and the molar ratio of $\mathrm{MnO}_{2}$ and $\mathrm{Al}$ is about 1:5. But the molar ratio of $\mathrm{MnO}_{2}$ and $\mathrm{Al}$ should be about $3: 4$ from the chemical equation. Recently, Kelsey and coworkers choose $\mathrm{Mg}$ powder as the fuel rather than $\mathrm{Al}$ powder to study the effects of rheological properties on the reactivity of energetic thin films of $\mathrm{MnO}_{2}-\mathrm{Mg}$ [15]. But in terms of application security, the stability of $\mathrm{Al}$ powder is better than Mg powder. Namely, $\mathrm{Al}$ powder has a relatively lower sensitivity than $\mathrm{Mg}$ powder. Therefore, we are much interested in $\mathrm{MnO}_{2}$ - $\mathrm{Al}$ thermite system.

Although so many previous studies have shown the properties and performances of many types of thermite system, the effect of Al particles size on thermal behavior and kinetics of $\mathrm{Al}-\mathrm{MnO}_{2}$ thermite system has not been well documented. Besides, the thermal process of micron- $\mathrm{MnO}_{2}$ is significantly different from other ordinary metal oxidizers, such as $\mathrm{CuO}, \mathrm{Fe}_{2} \mathrm{O}_{3}, \mathrm{MoO}_{3}$, and $\mathrm{WO}_{3}$. Micron- $\mathrm{MnO}_{2}$ has two processes of thermal decomposition at the range of room temperature to $900^{\circ} \mathrm{C}$ [16-18]. In this work, the thermite systems of different $\mathrm{Al}$ particle sizes mixed with micron- $\mathrm{MnO}_{2}$ were prepared by ultrasonic dispersion method. Based on the TG-DSC tests at different heating rates, the famous Kissinger method was chosen to calculate the activation energy of the samples preliminarily at their first exothermic peaks. The objectives of this study are to figure out the changes of thermal behavior and kinetics of $\mathrm{Al}$ and micron- $\mathrm{MnO}_{2}$ thermite system with different $\mathrm{Al}$ particles sizes.

\section{Experimental}

2.1. Materials and Sample Preparation. All chemicals were analytical reagent grade and were used without any further treatment or purification. The micron- $\mathrm{MnO}_{2}(5 \mu \mathrm{m})$ and $\mathrm{Al}$ powders (5 and $1 \mu \mathrm{m}, 100-200 \mathrm{~nm}$ ) were purchased from Nai-ou Nano Technology Co., Ltd. (Shanghai, China). The absolute ethyl alcohol was purchased from Sinopharm Chemical Reagent Co., Ltd. (Shanghai, China).

In this paper, the purity of $\mathrm{Al}$ powder should be tested by using TG-DSC under air atmosphere before preparing the thermite samples. Then, thermite mixtures of Al with different particles size and $\mathrm{MnO}_{2}$ are prepared using ultrasonic dispersion method. In order to make full use of $\mathrm{MnO}_{2}$ oxidizer, the fuel-rich formula was selected. The $\mathrm{Al} / \mathrm{MnO}_{2}$ mixture dispersed in absolute ethyl alcohol was sonicated for $60 \mathrm{~min}$ in a sonic bath to prepare a homogeneously dispersed solution. After sonication, the slurry was dried at $60^{\circ} \mathrm{C}$ for $12 \mathrm{~h}$ in vacuum oven.
2.2. FE-SEM and XRD Analysis. The morphology, particle size, and mixing quality of the materials and mixtures were characterized by field emission scanning electron microscopy (FE-SEM) analysis (HITACHI S-4800 II, Japan, and Zeiss EVO, Germany). The phase structures of thermite samples and the reaction products were tested by using $\mathrm{X}$-ray diffraction (XRD) analysis (Bruker, D8 Advance, Germany).

2.3. Thermal and Kinetics Analysis. Investigations of thermal behavior of the pure compounds and mixtures were carried out using the TG-DSC simultaneous thermal analyzer (NETZSCH STA 449F3, Germany). As for the pure compounds, the heating rate was $10^{\circ} \mathrm{C} \cdot \mathrm{min}^{-1}$. And as for the $\mathrm{Al} /$ $\mathrm{MnO}_{2}$ mixtures, the heating rates were 8,10 , and $14^{\circ} \mathrm{C} \cdot \mathrm{min}^{-1}$ (covering the temperature range from room temperature to $\left.1000^{\circ} \mathrm{C}\right)$. Nitrogen atmosphere was chosen as purge and protective gas.

In this work, the famous Kissinger method was used in the calculation of thermal kinetics of the $\mathrm{Al} / \mathrm{MnO}_{2}$ thermite mixtures. The activation energy was calculated through Kissinger method based on the DSC peak temperature [19-21]. This method can be expressed by the following equation:

$$
\operatorname{In}\left(\frac{\beta}{T_{p}^{2}}\right)=\operatorname{In} \frac{A R}{E_{a}}-\frac{E_{a}}{R T_{p}},
$$

where $\beta$ is the linear heating rate $\left({ }^{\circ} \mathrm{C} \min ^{-1}\right), T_{p}$ the absolute temperature of DSC peak temperature $(\mathrm{K}), R$ the universal gas constant $\left(\mathrm{J} \cdot \mathrm{mol}^{-1} \cdot \mathrm{K}^{-1}\right), A$ the preexponential factor $\left(\mathrm{s}^{-1}\right)$, and $E_{a}$ the activation energy $\left(\mathrm{kJ} \cdot \mathrm{mol}^{-1}\right)$. Thus, the plot of In $\left(\beta / T_{p}^{2}\right)$ versus $1 / T_{p}$ should be a straight line whose slope can be used to evaluate the activation energy. The degree of credibility will be higher if the absolute value of the correlation coefficient is much closer to 1 theoretically.

\section{Results and Discussion}

3.1. Thermal Properties of Micron- $\mathrm{MnO}_{2}$. In order to verify the thermal decomposition of the pure $5 \mu \mathrm{m} \mathrm{MnO}_{2}$, the TG and DSC curves of $33.564 \mathrm{mg} \mathrm{MnO}_{2}$ sample into the $80 \mu \mathrm{L}$ corundum crucibles are obtained in nitrogen atmosphere from room temperature to $900^{\circ} \mathrm{C}$, as shown in Figure 1. In Figure 1, the process of thermal decomposition can be divided into two steps.

The first step of thermal decomposition takes place between $507.3^{\circ} \mathrm{C}$ and $598.1^{\circ} \mathrm{C}$ with a sharp mass loss of about $8.60 \%$ because of $\mathrm{O}_{2}$ production. The heat release of the first decomposition step is about $-197.1 \mathrm{Jg}^{-1}$. Besides, the second step of thermal decomposition takes place between $734.6^{\circ} \mathrm{C}$ and $842.6^{\circ} \mathrm{C}$ with a mass loss of about $3.07 \%$ because of $\mathrm{O}_{2}$ production, too. The heat release of the second decomposition step is about $-57.4 \mathrm{Jg}^{-1}$. According to the previous studies, the thermal decomposition of $\mathrm{MnO}_{2}$ can be summarized as follows: [16-18].

$$
\mathrm{MnO}_{2} \underset{500 \sim 600^{\circ} \mathrm{C}}{\stackrel{\text { first-step }}{\longrightarrow}} \mathrm{Mn}_{2} \mathrm{O}_{3} \underset{730 \sim 850^{\circ} \mathrm{C}}{\stackrel{\text { sceond-step }}{\longrightarrow}} \mathrm{Mn}_{3} \mathrm{O}_{4}
$$




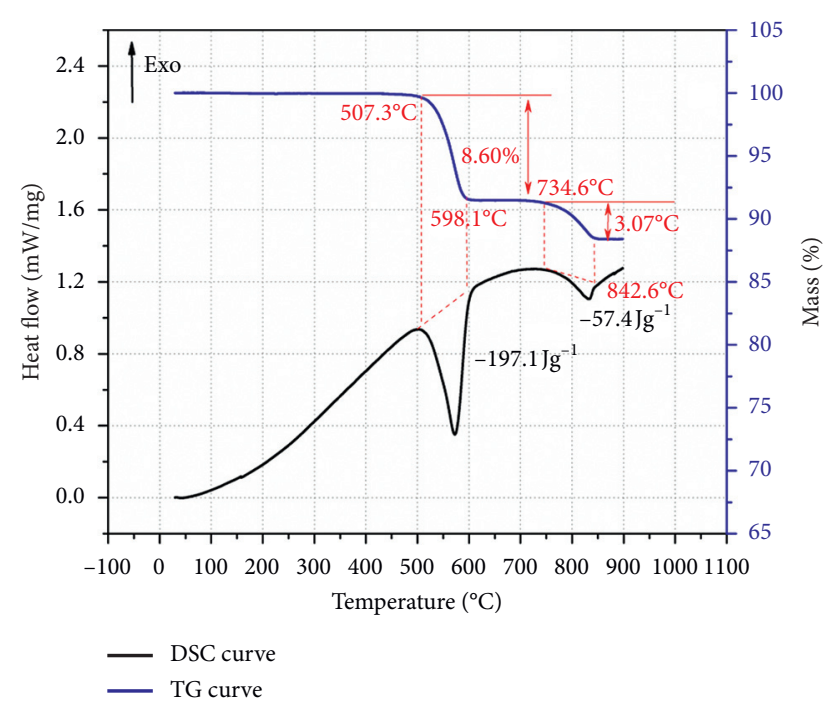

FIgURE 1: TG-DSC curves of micron- $\mathrm{MnO}_{2}$.

3.2. Purity of Al Powder Tests. In fact, the alumina shell effect on $\mathrm{Al}$ powder usually cannot be negligible simply, especially for the nano-Al powder. So, in order to figure out the purity of $\mathrm{Al}$ rigorously, the TG-DSC tests were carried out under air conditions with $10^{\circ} \mathrm{C} \cdot \mathrm{min}^{-1}$ heating rate, as shown in Figure 2. According to the reaction equation, the $\mathrm{Al}$ can be oxidized by gaseous $\mathrm{O}_{2}$ leading to the $\mathrm{Al}_{2} \mathrm{O}_{3}$ product, so theoretically the percentage increase in mass should be about $88.89 \%$. However, due to the existence of alumina shell, from room temperature to $1000^{\circ} \mathrm{C}$, the values of mass increase of $5 \mu \mathrm{m} \mathrm{Al}$ powder, $1 \mu \mathrm{m} \mathrm{Al}$ powder, and nano-Al powder are $57.27 \%$, 50.02\%, and $40.96 \%$, respectively. Namely, the purity of $5 \mu \mathrm{m} \mathrm{Al}$ powder is about $83.26 \%$ and purity of $1 \mu \mathrm{m}$ $\mathrm{Al}$ powder is about $79.42 \%$, while that of nano- $\mathrm{Al}$ powder is only about $74.62 \%$.

3.3. FE-SEM and XRD Analysis. Figure 3 shows FE-SEM images of the pure components. Particle shapes of $5 \mu \mathrm{m}$ $\mathrm{MnO}_{2}$ are shown in Figure 3(a); the particles are irregular polygon with partial agglomeration. The average $5 \mu \mathrm{m} \mathrm{Al}$ particles are shown in Figure 3(b) while the average $1 \mu \mathrm{m} \mathrm{Al}$ particles are shown in Figure 3(c), which belong to the micron-level Al powder. As shown in Figure 3(d), it is the morphology of nano-Al powder with the average diameter of 100-200 nm. Compared with the micron-level Al powder, the nano-Al powder shows the great mass of agglomeration.

Figure 4 shows SEM images of different thermite systems. The morphologies and distribution of $5 \mu \mathrm{m}$ $\mathrm{Al}+$ micron $-\mathrm{MnO}_{2}$ and $1 \mu \mathrm{m} \mathrm{Al}+$ micron- $\mathrm{MnO}_{2}$ thermite samples are shown in Figures 4(a) and 4(b), respectively, and the contact of $1 \mu \mathrm{m} \mathrm{Al}+$ micron- $\mathrm{MnO}_{2}$ thermite sample is more intimate than that of $5 \mu \mathrm{m} \mathrm{Al}+$ micron- $\mathrm{MnO}_{2}$ thermite sample. The nano- $\mathrm{Al}+$ micron- $\mathrm{MnO}_{2}$ thermite sample is shown in Figure $4(\mathrm{c})$. Since a large number of nano-Al particles attach to the surface of $\mathrm{MnO}_{2}$, the surface-area-tovolume ratio could increase a lot. Besides, the nano-Al particles still have the obvious agglomeration phenomenon.
Figure 5 shows the XRD results of thermite samples. The phases of $\mathrm{MnO}_{2}$ bulk in thermite systems are consistent with the tetragonal pyrolusite (ICDD/JCPDS 24-0735 MDI Jade 6.0). The space group is $\mathrm{P} 42 / \mathrm{mnm}$ (136), and the lattice constants are $a=b=4.399 \AA, c=2.874 \AA$. Besides, the selected $\mathrm{Al}$ powders at different particle sizes have the same phase from the XRD results, which are consistent with aluminum (ICDD/JCPDS 04-0787 MDI Jade 6.0). The space group is Fm-3m (225), and the lattice constants are $a=b=c=4.049 \AA$. The XRD results can rule out the effect of crystal shape on the thermal analysis of thermite samples.

3.4. Thermal Properties Analysis. The thermal properties of thermite samples were tested by using TG-DSC at $10^{\circ} \mathrm{C} \cdot \mathrm{min}^{-1}$ at nitrogen atmosphere, as shown in Figure 6.

Figure 6(a) represents the thermal behavior of $5 \mu \mathrm{m}$ $\mathrm{Al}+$ micron- $\mathrm{MnO}_{2}$ thermite sample from room temperature to $1000^{\circ} \mathrm{C}$. During the TG-DSC testing, there is no evident reaction or physical change from room temperature to $500^{\circ} \mathrm{C}$. As the test temperature rises further, there are six DSC peaks of A, B, C, D, E, and F sequentially in Figure 6(a). Endothermic peak A, from $512^{\circ} \mathrm{C}$ to $591^{\circ} \mathrm{C}$ and with peak temperature at $566^{\circ} \mathrm{C}$, is on behalf of the first decomposition of $\mathrm{MnO}_{2}$ due to the mass loss and endothermic process, which can be judged by TG curve. The products are $\mathrm{Mn}_{2} \mathrm{O}_{3}$ and gaseous $\mathrm{O}_{2}$ release leading to about $4.5 \%$ mass loss. However, according to the results of thermal decomposition of micron- $\mathrm{MnO}_{2}$ in Figure 1, if all of the micron- $\mathrm{MnO}_{2}$ in the thermite system has taken part in the decomposition, the loss of mass in this temperature interval should be apparently more than $4.7 \%$. Namely, some of $\mathrm{MnO}_{2}$ does not decompose at all but reacts with $5 \mu \mathrm{m} \mathrm{Al}$ powder with releasing a little heat at the same time, which should be exothermic peak B. The peak temperature of peak B is $594^{\circ} \mathrm{C}$ with only $57 \mathrm{Jg}^{-1}$ heat release. As for exothermic peak $\mathrm{C}$, there is a clear gap between peaks $B$ and $C$, indicating that peak $C$ is on behalf of different reaction process. It should be the reaction between $5 \mu \mathrm{m} \mathrm{Al}$ powder and products after decomposition of $\mathrm{MnO}_{2}$, part of $\mathrm{Mn}_{2} \mathrm{O}_{3}$ and part of gaseous $\mathrm{O}_{2}$ due to the mass increase a little, and the peak temperature is $626^{\circ} \mathrm{C}$. The above exothermic reactions appear before the Al powder melt, which belongs to solid-phase reaction. Endothermic peak D means the melt of $\mathrm{Al}$ at about $660^{\circ} \mathrm{C}$. Then, endothermic peak $\mathrm{E}$ appears with the mass loss further in TG curve, which means the second thermal decomposition of $\mathrm{MnO}_{2}$, from remaining $\mathrm{Mn}_{2} \mathrm{O}_{3}$ to $\mathrm{Mn}_{3} \mathrm{O}_{4}$ with gaseous $\mathrm{O}_{2}$ release. Next, at the temperature range $850^{\circ} \mathrm{C} \sim 960^{\circ} \mathrm{C}$, there is the main exothermic peak $\mathrm{F}$, which is thermite reaction between molten $\mathrm{Al}$ and $\mathrm{Mn}_{3} \mathrm{O}_{4}$ as well as part of generated $\mathrm{O}_{2}$. The peak temperature of peak $\mathrm{F}$ is at $943^{\circ} \mathrm{C}$. In summary, the $5 \mu \mathrm{m} \mathrm{Al}+$ micron $-\mathrm{MnO}_{2}$ thermite system shows the low reactivity, which might be because the distance between the fuel and oxidizer is not close enough from SEM image.

In Figure 6(b), it is the TG-DSC results of $1 \mu \mathrm{m}$ $\mathrm{Al}+$ micron $-\mathrm{MnO}_{2}$ thermite sample at the same conditions. Similarly, there is no evident reaction or physical change from room temperature to $450^{\circ} \mathrm{C}$. But as the test temperature 


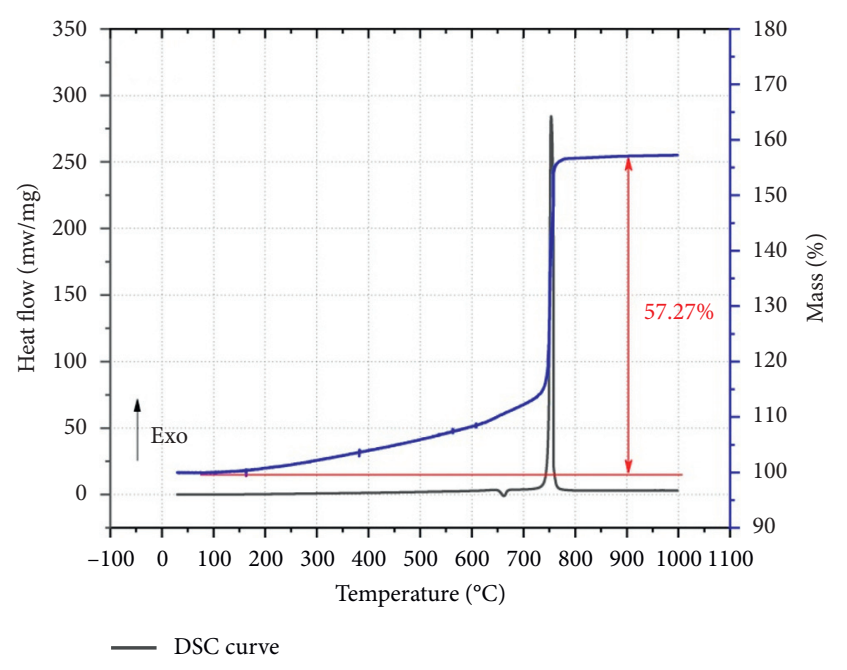

- DSC curve

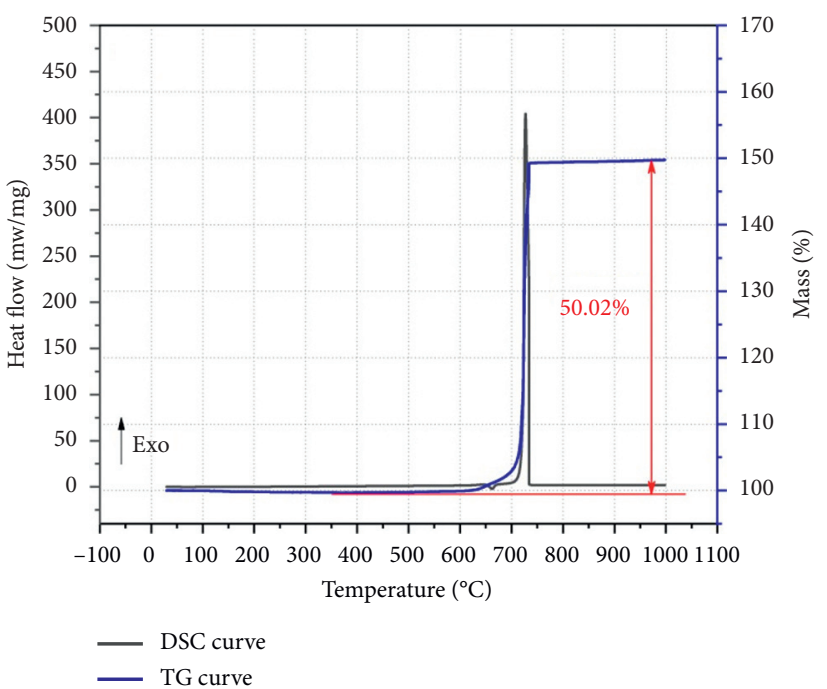

(b)

(a)

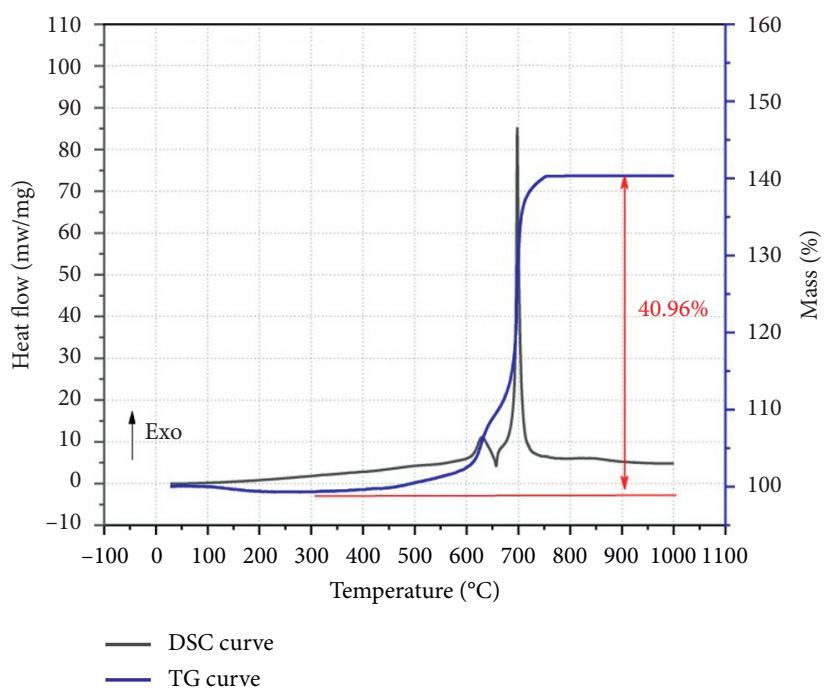

(c)

Figure 2: TG-DSC curves of different particle sizes of Al powder at air atmosphere: (a) $5 \mu \mathrm{m} \mathrm{Al} \mathrm{powder,} \mathrm{(b)} 1 \mu \mathrm{m} \mathrm{Al} \mathrm{powder,} \mathrm{and} \mathrm{(c)} \mathrm{nano-Al}$ powder.

rises further, there are five DSC peaks of $\mathrm{A}, \mathrm{B}, \mathrm{C}, \mathrm{D}$, and $\mathrm{E}$ sequentially in Figure 6(b). Compared with the peaks of $5 \mu \mathrm{m} \mathrm{Al}+$ micron- $\mathrm{MnO}_{2}$ thermite sample in Figure 6(a), the first four peaks, A, B, C, and D, are similar, indicating the same processes. Endothermic peak A, from $475^{\circ} \mathrm{C}$ to $593^{\circ} \mathrm{C}$, means the first thermal decomposition of $\mathrm{MnO}_{2}$. Exothermic peak $\mathrm{B}$ represents the thermite reaction between $\mathrm{MnO}_{2}$ and $1 \mu \mathrm{m} \mathrm{Al}$ powder while exothermic peak $\mathrm{C}$ is the redox reaction between $1 \mu \mathrm{m} \mathrm{Al}$ powder and part of $\mathrm{Mn}_{2} \mathrm{O}_{3}$ as well as part of gaseous $\mathrm{O}_{2}$. But the difference is that more $\mathrm{MnO}_{2}$ is involved in the $\mathrm{Al}-\mathrm{MnO}_{2}$ thermite reaction directly judged from the more heat release from peak $\mathrm{B}$, about $193 \mathrm{Jg}^{-1}$ and less mass loss in TG curve, only about $4.1 \%$. Undoubtedly, endothermic peak $\mathrm{D}$ is the melting process of $\mathrm{Al}$ powder. However, as for exothermic peak E in Figure 6(b), it is the main difference from Figure 6(a). Both DSC curve and TG curve show that the further thermal decomposition does not happen. There is not any endothermic signal or mass loss signal. There is only an obvious exothermic peak $\mathrm{E}$ at the temperature range $788^{\circ} \mathrm{C}$ to $882^{\circ} \mathrm{C}$, and the peak temperature of peak $\mathrm{E}$ is at $833^{\circ} \mathrm{C}$ in advance. Namely, all of the remaining $\mathrm{Mn}_{2} \mathrm{O}_{3}$ reacts with the molten $\mathrm{Al}$ directly with $418 \mathrm{Jg}^{-1}$ heat release. So, if the $\mathrm{Al}$ powder particle sizes decrease to $1 \mu \mathrm{m}$, the reactivity of the whole thermite system increases greatly. More $\mathrm{MnO}_{2}$ reacts with $\mathrm{Al}$ powder directly, and all of remaining $\mathrm{Mn}_{2} \mathrm{O}_{3}$ reacts with molten $\mathrm{Al}$ rather than the further decomposition.

In Figure 6(c), the nano-Al powder is introduced to the $\mathrm{Al}-\mathrm{MnO}_{2}$ thermite system. At the beginning of the TG-DSC, there is a slight mass loss in the TG curve, about $0.89 \%$, from room temperature to $300^{\circ} \mathrm{C}$ without any evident DSC signal, which is due to the desorption of $\mathrm{H}_{2} \mathrm{O}$ and ethyl alcohol on the surface of nano-Al powder [22, 23]. In contrast, there are merely four peaks in DSC curve, peaks A, B, C, and D. As for 

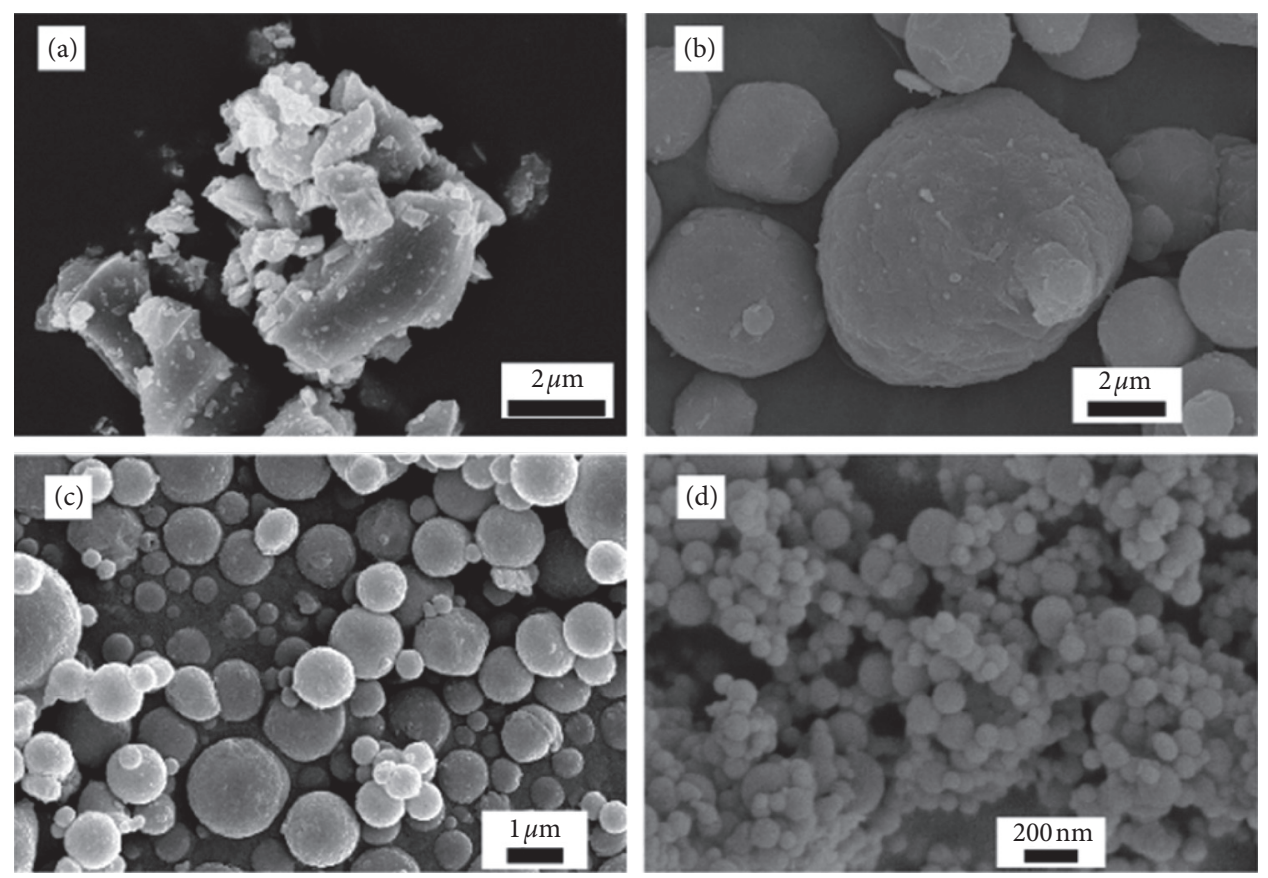

FIGURE 3: SEM images for the components: (a) micron- $\mathrm{MnO}_{2}$, (b) $5 \mu \mathrm{m} \mathrm{Al}$ powder, (c) $1 \mu \mathrm{m} \mathrm{Al}$ powder, and (d) nano-Al powder.
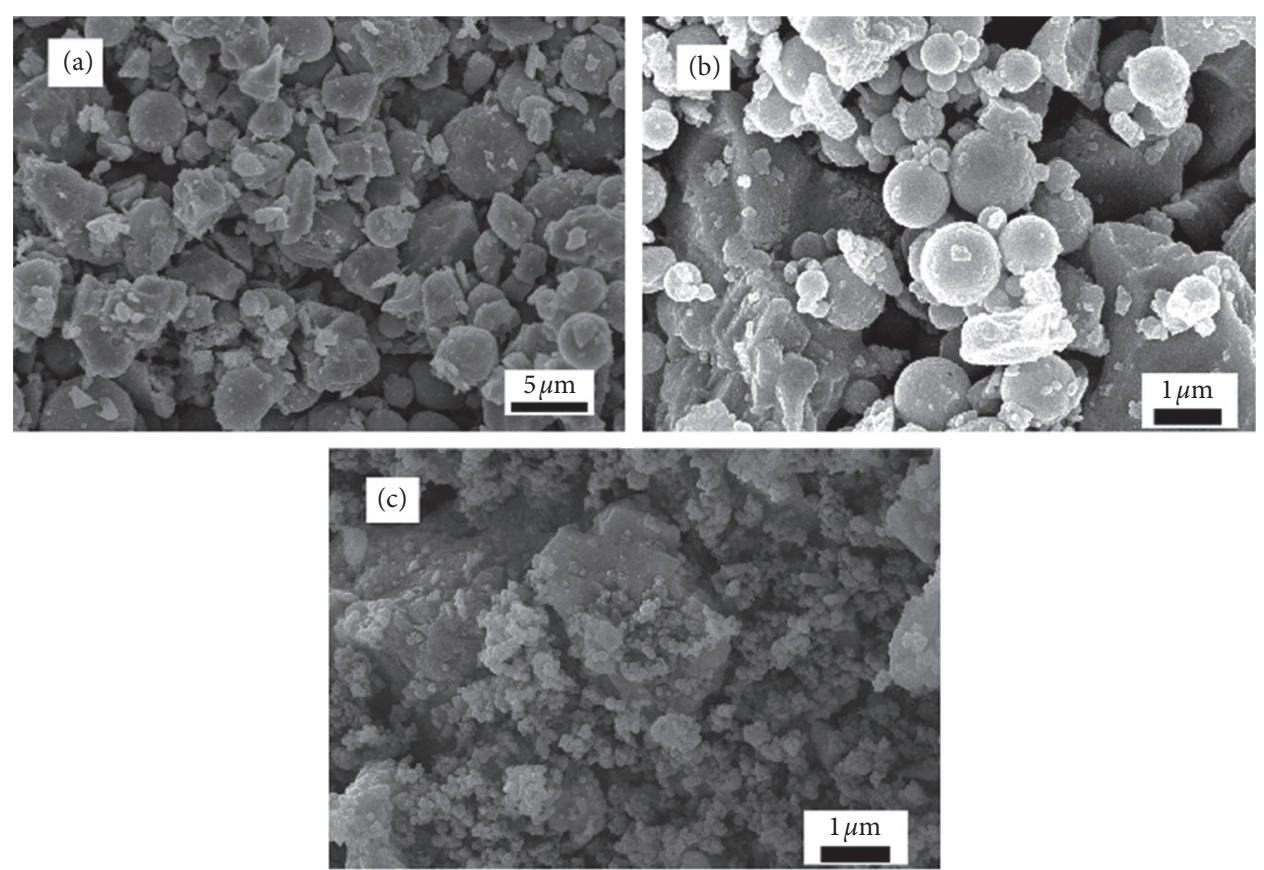

FIGURE 4: SEM images of thermite samples: (a) $5 \mu \mathrm{m} \mathrm{Al}+$ micron- $\mathrm{MnO}_{2}$ thermite sample, (b) $1 \mu \mathrm{m} \mathrm{Al}+$ micron- $\mathrm{MnO}_{2}$ thermite sample, and (c) nano- $\mathrm{Al}+$ micron- $\mathrm{MnO}_{2}$ thermite sample.

peak $\mathrm{A}$, it becomes an exothermic peak rather than an endothermic peak in Figures 6(a) or 6(b). The heat release reaches about $735 \mathrm{Jg}^{-1}$, and the temperature range is from $503^{\circ} \mathrm{C}$ to $591^{\circ} \mathrm{C}$. At the same time, as for TG curve, no significant mass loss or mass gain can be found at the range of temperature from $300^{\circ} \mathrm{C}$ to $600^{\circ} \mathrm{C}$, namely, all of $\mathrm{MnO}_{2}$ takes part in the thermite reaction at solid-phase state rather than the first thermal decomposition. The thermite reaction, meaning oxygen transfer from the $\mathrm{MnO}_{2}$ to the $\mathrm{Al}$, should not exhibit any change in the mass signal due to conservation of mass. No other mass loss can be found as temperature rises further, which means that all of the $\mathrm{MnO}_{2}$ is consumed in the first main thermite reaction. Then, after the thermite reaction, exothermic peak $\mathrm{A}$, there are still three 


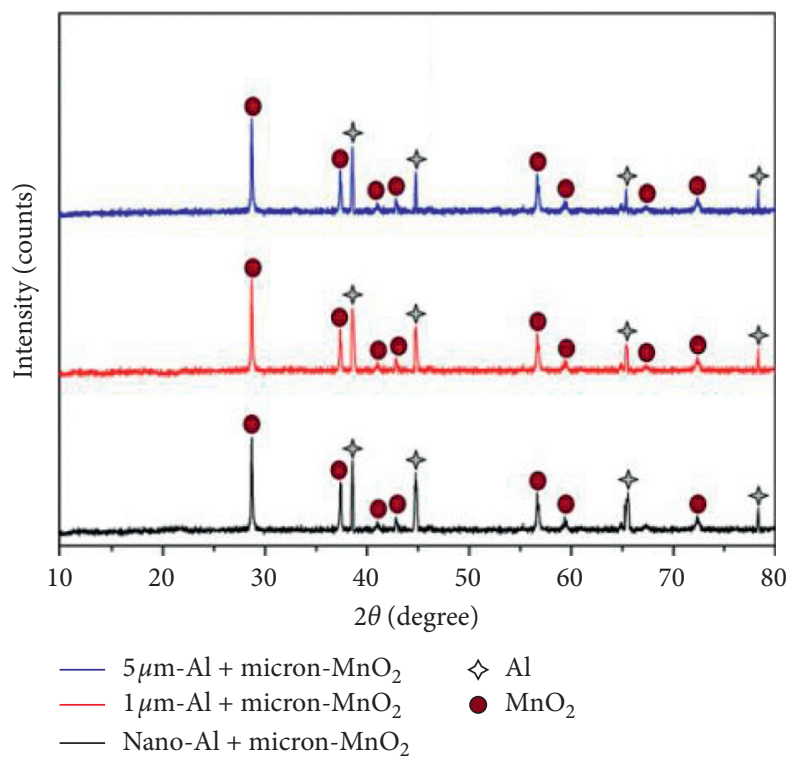

FIGURE 5: XRD pattern of the thermite samples.

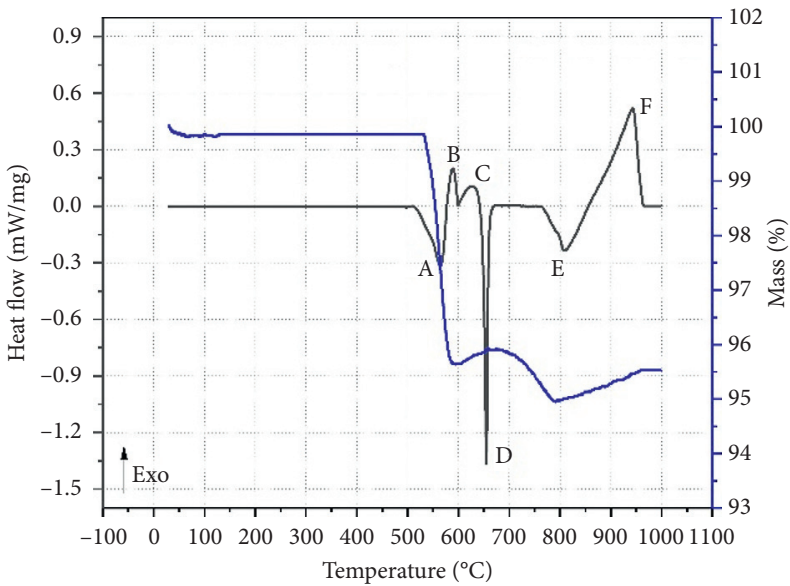

- DSC curve

- TG curve

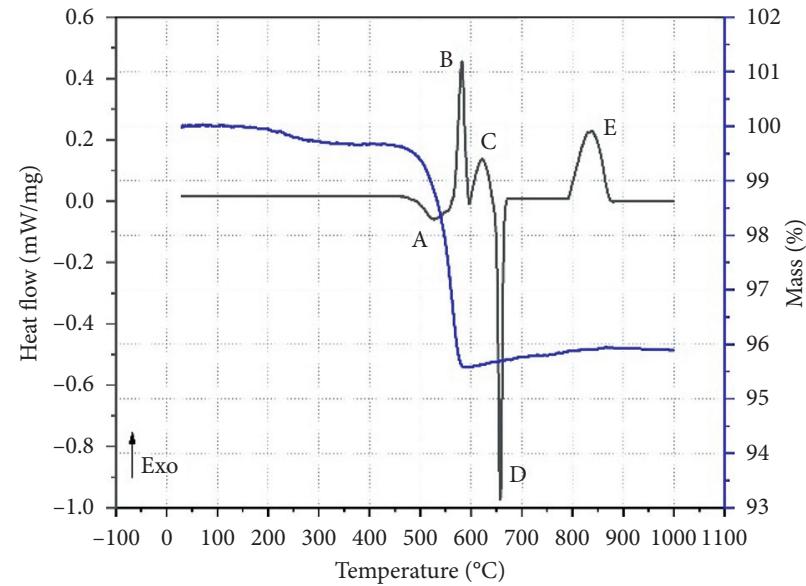

- DSC curve

(a)

(b)

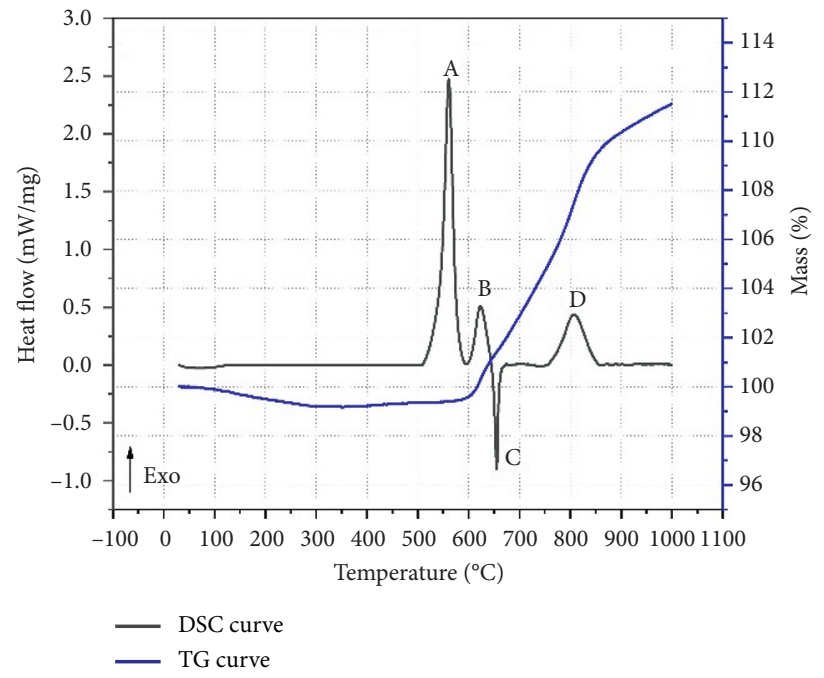

(c)

Figure 6: TG-DSC curves of thermite samples with different $\mathrm{Al}$ particle sizes: (a) $5 \mu \mathrm{m} \mathrm{Al}+$ micron- $\mathrm{MnO}_{2}$ thermite sample, (b) $1 \mu \mathrm{m}$ $\mathrm{Al}+$ micron- $\mathrm{MnO}_{2}$ thermite sample, and (c) nano- $\mathrm{Al}+$ micron- $\mathrm{MnO}_{2}$ thermite sample. 


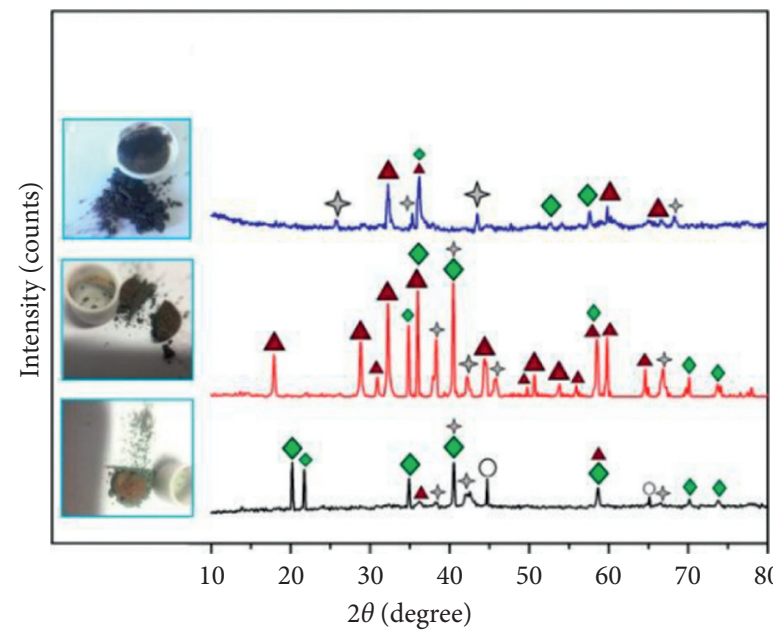
$\diamond \mathrm{Al}_{2} \mathrm{O}_{3}$
- $5 \mu \mathrm{m}-\mathrm{Al}+$ micron $-\mathrm{MnO}_{2}$
O AIN
- $1 \mu \mathrm{m}-\mathrm{Al}+$ micron- $\mathrm{MnO}_{2}$
$\diamond \mathrm{MnO}$
- Nano- $\mathrm{Al}+$ micron- $\mathrm{MnO}_{2}$
- $\mathrm{Mn}_{3} \mathrm{O}_{4}$

FIGURE 7: XRD pattern of the reaction products.

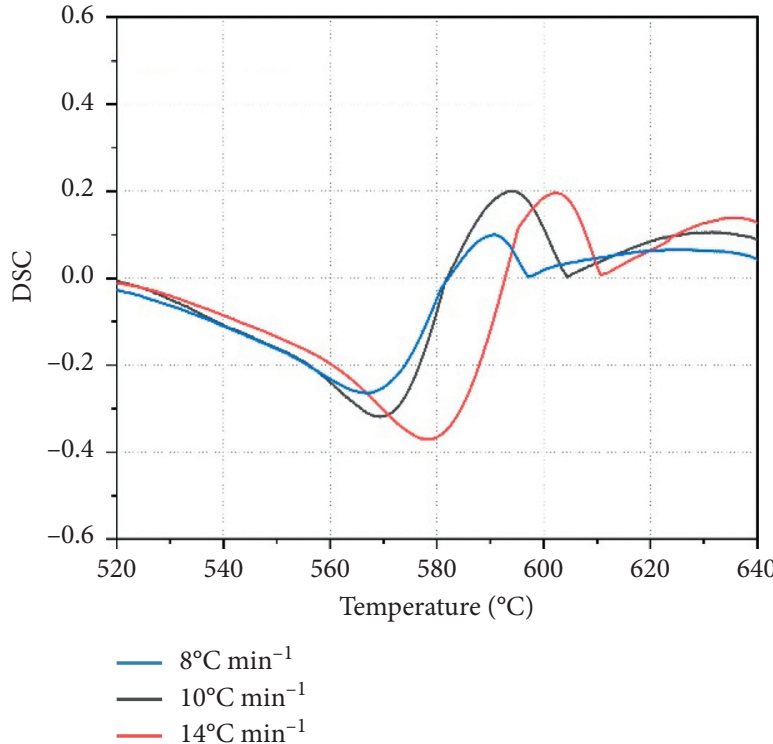

(a)

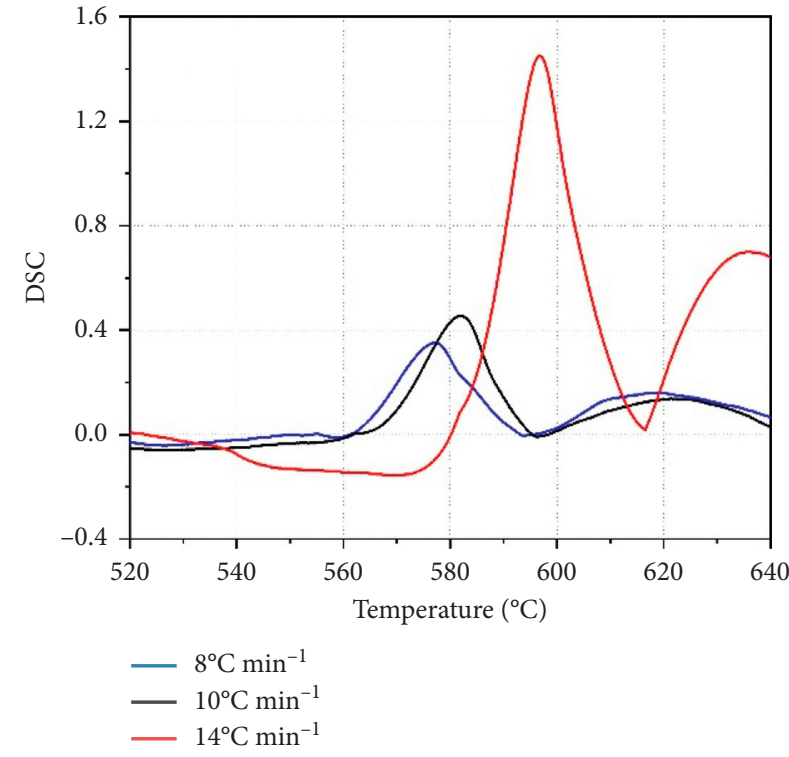

(b)

FIgURE 8: Continued. 


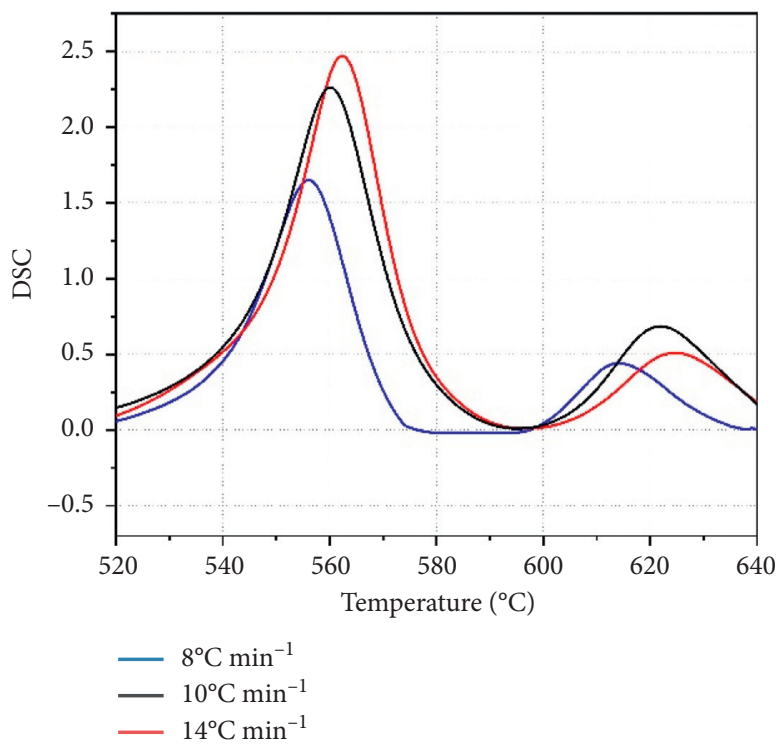

(c)

FiguRE 8: DSC curves of thermite samples at different heating rates: (a) $5 \mu \mathrm{m} \mathrm{Al}+$ micron- $\mathrm{MnO}_{2}$ thermite, (b) $1 \mu \mathrm{m} \mathrm{Al}+\mathrm{micron}^{-\mathrm{MnO}_{2}}$ thermite, and (c) nano- $\mathrm{Al}+$ micron- $\mathrm{MnO}_{2}$ thermite.

TABLE 1: DSC parameters of first exothermic peaks.

\begin{tabular}{|c|c|c|c|c|}
\hline \multirow{2}{*}{ Sample formula } & \multicolumn{3}{|c|}{ Heating rates $\left({ }^{\circ} \mathrm{C} \cdot \mathrm{min}^{-1}\right)$} & \multirow[b]{2}{*}{ Average heat release } \\
\hline & 8 & $\begin{array}{c}10 \\
\text { npera }\end{array}$ & 14 & \\
\hline $5 \mu \mathrm{m} \mathrm{Al}+$ micron- $\mathrm{MnO}_{2}$ & 591 & 594 & 602 & $59 \mathrm{Jg}^{-1}$ \\
\hline $1 \mu \mathrm{m} \mathrm{Al}+$ micron $-\mathrm{MnO}_{2}$ & 578 & 583 & 597 & $227 \mathrm{Jg}^{-1}$ \\
\hline Nano-Al + micron- $\mathrm{MnO}_{2}$ & 556 & 561 & 563 & $759 \mathrm{Jg}^{-1}$ \\
\hline
\end{tabular}

peaks, exothermic peaks $\mathrm{B}$ and $\mathrm{D}$ and endothermic peak $\mathrm{C}$. Clearly, endothermic peak $\mathrm{C}$ is due to the melting of $\mathrm{Al}$ powder. As for exothermic peaks $B$ and $D$, they should be the reaction between nano-Al and $\mathrm{N}_{2}$ with the product of aluminum nitride (AlN) since the obvious mass gain in the TG curve. Since the TG-DSC is running in the nitrogen atmosphere and the mass gain is due to the reaction of the $\mathrm{Al}$ to nitrogen in the environment, AlN is produced, releasing part of the heat [24].

At the end of the TG-DSC tests, the residues in the crucibles are collected, and the reaction products are tested by using XRD analysis, as shown in Figure 7. The phases of reaction production in $5 \mu \mathrm{m} \mathrm{Al}+$ micron- $\mathrm{MnO}_{2}$ thermite sample are mainly $\mathrm{Mn}_{3} \mathrm{O}_{4}$ and part of $\mathrm{MnO}$. When the particle size of $\mathrm{Al}$ powder decreases to $1 \mu \mathrm{m}$, the main reaction products still are $\mathrm{Mn}_{3} \mathrm{O}_{4}$ and $\mathrm{MnO}$, but the mass fraction of $\mathrm{MnO}$ in residues increases. Based on the results of thermal analysis in Figure 6, a certain part of $\mathrm{Mn}_{3} \mathrm{O}_{4}$ in the residues of $5 \mu \mathrm{m} \mathrm{Al}+$ micron- $\mathrm{MnO}_{2}$ thermite sample should decompose from the $\mathrm{Mn}_{2} \mathrm{O}_{3}$ while most of $\mathrm{Mn}_{3} \mathrm{O}_{4}$ in the residues of $1 \mu \mathrm{m} \mathrm{Al}+$ micron- $\mathrm{MnO}_{2}$ thermite sample could be the reaction products from the thermite reaction between $\mathrm{Mn}_{2} \mathrm{O}_{3}$ and molten $\mathrm{Al}$, which also reflects the different reactivity between the above two thermite samples. As for nano- $\mathrm{Al}+$ micron- $\mathrm{MnO}_{2}$ thermite sample, the residues are mainly $\mathrm{MnO}$ with only little $\mathrm{Mn}_{3} \mathrm{O}_{4}$. Namely, nano-Al powder has much more reactivity, so it could make full use of the $\mathrm{O}$ element in the oxidizer $\mathrm{MnO}_{2}$.

3.5. Activation Energy. In order to make a further comparison of kinetics, the thermite samples were also tested by DSC at different heating rates. The thermite has a phenomenon of self-propagating combustion once it ignites successfully, namely, the first exothermic peak temperature is important in practice, as shown in Figure 8, and the peak temperature points are listed in Table 1.

As seen in Table 1, in terms of peak temperature for the different sample components, the peak temperature decreases with the decrease of particle size of $\mathrm{Al}$ powder. When Al particle size enters nanolevel, peak temperature has a significant reduction, near $560^{\circ} \mathrm{C}$. However, the average heat release is the opposite of peak temperature. Namely, the average heat release increases with the decrease of particle size of $\mathrm{Al}$ powder.

The Kissinger method is one of the dominant methods in the maximum rate methods (peak methods) [25, 26]. Based upon Kissinger method mentioned in equation (1), the plots of $\ln \left(\beta / T_{2}\right)$ vs. $1 / T_{p}$ at the peak temperature with the different $\mathrm{Al}$ particles size are constructed in Figure 9. The 


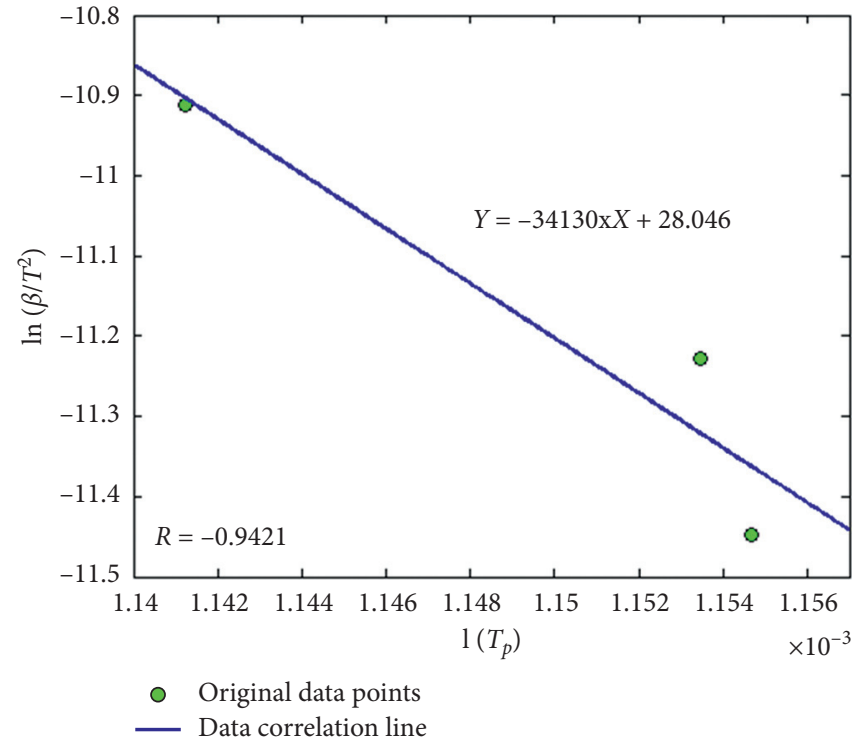

(a)

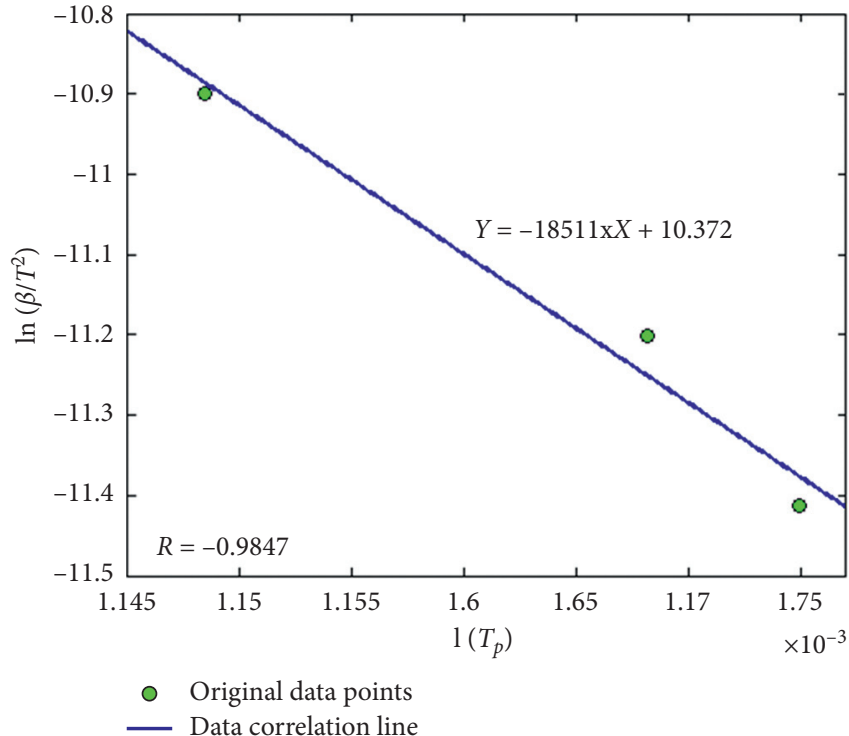

(b)

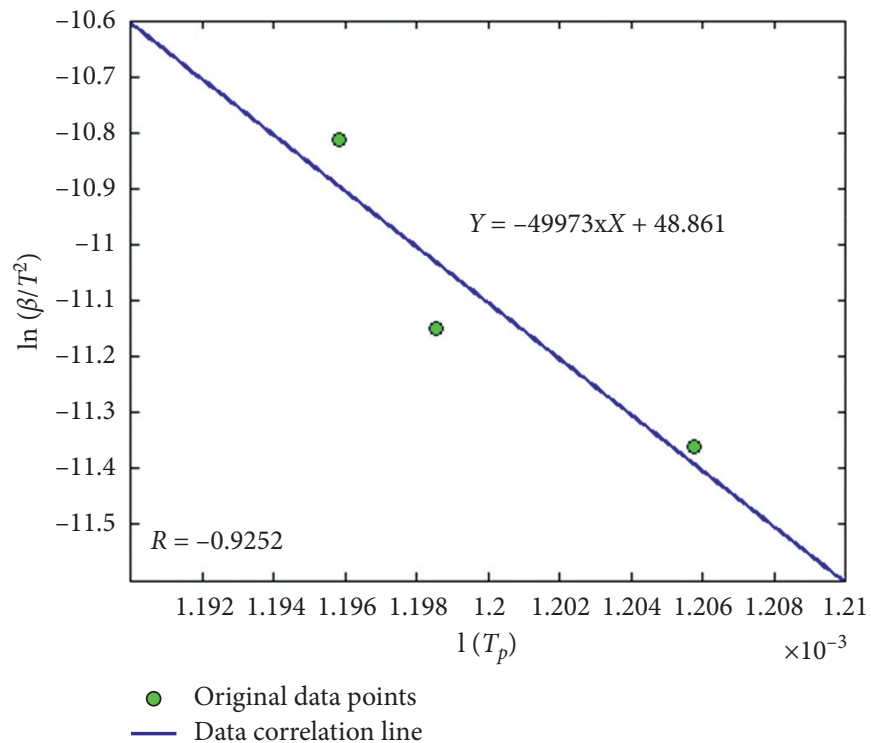

(c)

Figure 9: The data correlation line of $\ln (\beta / \mathrm{T} 2)$ vs. $1 / \mathrm{T}_{p}$ : (a) $5 \mu \mathrm{m} \mathrm{Al}+$ micron- $\mathrm{MnO}_{2}$ thermite, (b) $1 \mu \mathrm{m} \mathrm{Al}+$ micron- $\mathrm{MnO}_{2}$ thermite, and (c) nano- $\mathrm{Al}+$ micron- $\mathrm{MnO}_{2}$ thermite.

TABLE 2: The figures of activation energy $E_{\mathrm{a}}$

\begin{tabular}{|c|c|c|c|}
\hline Thermite formula & $5 \mu \mathrm{m} \mathrm{Al}$ micron- $\mathrm{MnO}_{2}$ & $1 \mu \mathrm{m} \mathrm{Al}$ micron- $\mathrm{MnO}_{2}$ & Nano-Al micron- $\mathrm{MnO}_{2}$ \\
\hline$E_{a}$ & $283.76 \mathrm{kJmol}^{-1}$ & $153.90 \mathrm{kJmol}^{-1}$ & $415.48 \mathrm{kJmol}^{-1}$ \\
\hline
\end{tabular}

absolute values of all correlation coefficient $R$ were above 0.94. And the figures of activation energy $E_{\mathrm{a}}$ were listed into Table 2, which were deduced from the slope of the data correlation line. According to Table 2, when the Al particle size decreased from $5 \mu \mathrm{m}$ to $1 \mu \mathrm{m}$, the activation energy of the thermite decreased. But if the Al particle size decreased further into the nanolevel, the activation energy of the thermite increased markedly. As known to all, the Al powder has an oxide layer coating on the surface. Usually, the thickness of oxide layer can greatly reduce the purity of nano-Al powder, which is corresponding with the results of purity tests in Figure 2. Namely, as for micron-level Al powder, the thickness of oxide layer has a very light proportion for $\mathrm{Al}$ powder $[26,27]$. The reduction of reactive $\mathrm{Al}$ purity in nano-Al particles could be one of the reasons for activation energy increase. Besides, the agglomeration of 
nano-Al particles cannot be ignored. Agglomeration could be very important for the characteristic of nano-level $\mathrm{Al}$ powder, such as ignition kinetics and heat diffusion. The large size agglomeration might ignite after very long delays or even never ignite during the whole combustion process [28]. Thus, the agglomeration will not only decrease the heat of reaction, but also greatly increase activation energy of thermite system [29-31]. So, the above two reasons could explain the phenomenon of the significant increase of activation energy of nano- $\mathrm{Al}+$ micron- $\mathrm{MnO}_{2}$ thermite sample.

\section{Conclusion}

In this paper, $\mathrm{Al}-\mathrm{MnO}_{2}$ thermite samples with three different kinds of $\mathrm{Al}$ particle sizes were prepared via ultrasonic dispersion method. Firstly, the thermal decomposition process of micron- $\mathrm{MnO}_{2}$ and the purity of $\mathrm{Al}$ powders were tested by using TG-DSC. The values of purity of $5 \mu \mathrm{m} \mathrm{Al}$ powder, $1 \mu \mathrm{m} \mathrm{Al}$ powder, and nano-Al powder were $83.26 \%$, $79.42 \%$, and $74.62 \%$. According to XRD analysis, the components in the thermite system were same, and the only difference was the particle sizes of fuel, $\mathrm{Al}$ powders, from the SEM images. On the basis of that, the fuel-rich thermite systems were tested for their thermal properties and performance. The results showed that $1 \mu \mathrm{m} \mathrm{Al}$ powder + micron $-\mathrm{MnO}_{2}$ thermite system has better reactivity than that of $5 \mu \mathrm{m} \mathrm{Al}$ powder + micron $-\mathrm{MnO}_{2}$ thermite system. The latter has six DSC peaks while the former has only five DSC peaks without the second endothermic peak of thermal decomposition. However, as for nano-Al powder + micron $-\mathrm{MnO}_{2}$ system, there are only four DSC peaks. Apart from the melting of $\mathrm{Al}$ powder, there is not any other endothermic peak. Namely, almost all of micron- $\mathrm{MnO}_{2}$ reacted with solid-state nano-Al powder directly. After collecting and testing the residues, the reaction products of $5 \mu \mathrm{m}$ Al powder + micron $-\mathrm{MnO}_{2}$ thermite system were mainly $\mathrm{Mn}_{3} \mathrm{O}_{4}$ and a little $\mathrm{MnO}$ while that of $1 \mu \mathrm{m} \mathrm{Al}$ powder + micron- $\mathrm{MnO}_{2}$ thermite system showed a bit more fraction of $\mathrm{MnO}$, but as for nano-Al powder + micron$\mathrm{MnO}_{2}$ thermite system, the residues were mainly $\mathrm{MnO}$ with little $\mathrm{Mn} 3 \mathrm{O} 4$, which reflected that nano-Al made full use of $\mathrm{O}$ element in oxidizer $\mathrm{MnO}_{2}$. However, the kinetics results showed that nano-Al powder + micron- $\mathrm{MnO}_{2}$ thermite system had the highest activation energy, which can be explained by low reactive $\mathrm{Al}$ purity and the agglomeration of $\mathrm{Al}$ nanoparticles. The results clearly showed the great different thermal processes and changes of $\mathrm{Al}-\mathrm{MnO}_{2}$ thermite samples with different particle sizes of Al powder.

\section{Data Availability}

The data used to support the findings of this study are available from the corresponding author upon request.

\section{Conflicts of Interest}

The authors declare that there are no conflicts of interest regarding the publication of this paper.

\section{Acknowledgments}

This work was supported by the National Natural Science Foundation, project no. 51673213, and National Natural Science Fund for Youth Science Foundation, project no. 517040204.

\section{References}

[1] T. Bazyn, P. Lynch, H. Krier, and N. Glumac, "Combustion measurements of fuel-rich aluminum and molybdenum oxide nano-composite mixtures," Propellants, Explosives, Pyrotechnics, vol. 35, no. 2, pp. 93-99, 2010.

[2] H. G. Zhu, H. Z. Wang, D. S. Xiong, Q. J. Sun, and S. Q. Wu, "Reactive mechanism of composites synthesized by XD method in $\mathrm{Al}-\mathrm{TiO}_{2}$ system," The Chinese Journal of Nonferrous Metals, vol. 2, pp. 205-209, 2005.

[3] L. Glavier, G. Taton, J.-M. Ducéré et al., "Nanoenergetics as pressure generator for nontoxic impact primers: comparison of $\mathrm{Al} / \mathrm{Bi} 2 \mathrm{O} 3, \mathrm{Al} / \mathrm{CuO}, \mathrm{Al} / \mathrm{MoO} 3$ nanothermites and $\mathrm{Al} /$ PTFE," Combustion and Flame, vol. 162, no. 5, pp. 1813-1820, 2015.

[4] K. S. Martirosyan, "Nanoenergetic gas-generators: principles and applications," Journal of Materials Chemistry, vol. 21, no. 26, pp. 9400-9405, 2011.

[5] C. Rossi, A. Estève, and P. Vashishta, "Nanoscale energetic materials," Journal of Physics and Chemistry of Solids, vol. 71, no. 2, pp. 57-58, 2010.

[6] N. H. Yen and L. Y. Wang, "Reactive metals in explosives," Propellants, Explosives, Pyrotechnics, vol. 37, no. 3, pp. 143155, 2012.

[7] X. Hu, X. Liao, L. Xiao, X. Jian, and W. Zhou, "High-energy pollen-like porous $\mathrm{Fe} 2 \mathrm{O} 3 / \mathrm{Al}$ thermite: synthesis and properties," Propellants, Explosives, Pyrotechnics, vol. 40, no. 6, pp. 867-872, 2015.

[8] K. B. Plantier, M. L. Pantoya, and A. E. Gash, "Combustion wave speeds of nanocomposite $\mathrm{Al} / \mathrm{Fe} 2 \mathrm{O} 3$ : the effects of $\mathrm{Fe} 2 \mathrm{O} 3$ particle synthesis technique," Combustion and Flame, vol. 140, no. 4, pp. 299-309, 2005.

[9] J. Sun, M. L. Pantoya, and S. L. Simon, "Dependence of size and size distribution on reactivity of aluminum nanoparticles in reactions with oxygen and MoO3," Thermochimica Acta, vol. 444, no. 2, pp. 117-127, 2006.

[10] W. L. Perry, B. L. Smith, C. J. Bulian et al., "Nano-scale tungsten oxides for metastable intermolecular composites," Propellants, Explosives, Pyrotechnics, vol. 29, no. 2, pp. 99-105, 2004.

[11] D. K. Kim, J. H. Bae, M. K. Kang, and H. J. Kim, “Analysis on thermite reactions of $\mathrm{CuO}$ nanowires and nanopowders coated with Al," Current Applied Physics, vol. 11, no. 4, pp. 1067-1070, 2011.

[12] A. Prakash, A. Mccormick, and M. Zachariah, "Synthesis and reactivity of a super-reactive metastable intermolecular composite formulation of $\mathrm{Al} / \mathrm{KMnO}_{4}$," Advanced Materials, vol. 17, pp. 900-903, 2005.

[13] S. H. Fischer and M. C. Grubelich, A Survey of Combustible Metals, Thermites, and Intermetallics for Pyrotechnic Applications, Defense Technical Information Center, Fort Belvoir, VA, USA, 1996.

[14] B. Sarangi, R. R. Dash, and H. S. Ray, "Estimation of isothermal values of activation energy for aluminothermic reduction," Metallurgical and Materials Transactions B, vol. 29, no. 5, pp. 1135-1136, 1998. 
[15] K. A. Meeks, B. R. Clark, J. E. Cano, C. A. Apblett, and M. L. Pantoya, "Effects of rheological properties on reactivity of energetic thin films," Combustion and Flame, vol. 162, no. 9, pp. 3288-3293, 2015.

[16] B. Liu, P. S. Thomas, A. S. Ray, and R. P. Williams, "The effect of sampling conditions on the thermal decomposition of electrolytic manganese dioxide," Journal of Thermal Analysis and Calorimetry, vol. 76, no. 1, pp. 115-122, 2004.

[17] J. B. Fernandes, B. D. Desai, and V. N. K. Dalal, "Manganese dioxide-a review of a battery chemical part I. Chemical syntheses and X-ray diffraction studies of manganese dioxides," Journal of Power Sources, vol. 15, no. 4, pp. 209-237, 1985.

[18] K. Terayama and M. Ikeda, "Study on thermal decomposition of MnO," Transactions of the Japan Institute of Metals, vol. 24, no. 11, pp. 754-758, 1983.

[19] P. E. Sánchez-Jiménez, J. M. Criado, and L. A. PérezMaqueda, "Kissinger kinetic analysis of data obtained under different heating schedules," Journal of Thermal Analysis and Calorimetry, vol. 94, pp. 427-432, 2008.

[20] H. E. Kissinger, "Reaction kinetics in differential thermal analysis," Analytical Chemistry, vol. 29, pp. 1702-1706, 1957.

[21] P. G. Boswell, "On the calculation of activation energies using a modified Kissinger method," Journal of Thermal Analysis, vol. 18, pp. 353-358, 1980.

[22] A. V. Fraioli, "Investigation of manganese dioxide as an improved solid desiccant," Proceedings of the Electrochemical Society, vol. 85, pp. 342-351, 1985.

[23] R. A. Williams, M. Schoenitz, A. Ermoline, and E. L. Dreizin, "Low-temperature exothermic reactions in fully-dense $\mathrm{Al} /$ $\mathrm{MoO}_{3}$ nanocomposite powders," Thermochimica Acta, vol. 594, pp. 1-12, 2014.

[24] T. Sakurai, O. Yamada, and Y. M. Miyamoto, "Combustion synthesis of fine AlN powder and its reaction control," $M a$ terials Science and Engineering: A, vol. 415, pp. 40-47, 2006.

[25] M. J. Straink, "The determination of activation energy from linear heating rate experiments: a comparison of the accuracy of isoconversion methods," Thermochimica Acta, vol. 404, pp. 163-176, 2003.

[26] D. S. Sundaram, V. Yang, T. L. Connell, A. Risha, and R. A. Yetter, "Flame propagation of nano/micron-sized aluminum particles and ice (ALICE) mixtures," Proceedings of the Combustion Institute, vol. 34, pp. 2221-2228, 2013.

[27] L. J Zeng, "Effect of particle size of nano-aluminum powder on oxide film thickness and active aluminum content," Chinese Journal of Explosives \& Propellants, vol. 34, pp. 26-30, 2011.

[28] E. L. Dreizin, "Metal-based reactive nanomaterials," Progress in Energy and Combustion Science, vol. 35, pp. 141-167, 2009.

[29] A. Singhal, G. Skandan, A. Wang, N. Glumac, B. H. Kear, and R. D. Hunt, "On nanoparticle aggregation during vapor phase synthesis," Nanostructured Materials, vol. 11, pp. 545-552, 1999.

[30] S. G. Hosseini, A. Sheikhpour, M. H. Keshavarz, and S. Tavangar, "The effect of metal oxide particle size on the thermal behavior and ignition kinetic of $\mathrm{Mg}-\mathrm{CuO}$ thermite mixture," Thermochimica Acta, vol. 626, pp. 1-8, 2016.

[31] C. Rossi, K. Zhang, D. Esteve, P. Alphonse, P. Tailhades, and C. Vahlas, "Nanoenergetic materials for MEMS: a review," Journal of Microelectromechanical Systems, vol. 16, pp. 919931, 2007. 